\title{
Hispanismes
}

Revue de la Société des Hispanistes Français

$17 \mid 2021$

Murs, barrières, obstacles dans les mondes

hispaniques I

\section{Hilos conductores en la educación en México entre el Porfiriato y la posrevolución}

El ejemplo del «Método Best»

Fils conducteurs dans l'éducation mexicaine entre le Porfiriato et la post-

révolution: l'exemple de la "Méthode Best"

Threads in Mexican education between the Porfiriato and the post-revolutionary era: the example of the "Best Method"

\section{Élodie Vaudry}

\section{(2) OpenEdition}

\section{Journals}

Edición electrónica

URL: https://journals.openedition.org/hispanismes/13700

DOI: 10.4000/hispanismes. 13700

ISSN: 2270-0765

Editor

Société des Hispanistes Français

Referencia electrónica

Élodie Vaudry, «Hilos conductores en la educación en México entre el Porfiriato y la posrevolución», Hispanismes [En línea], 17 | 2021, Publicado el 01 junio 2021, consultado el 27 enero 2022. URL: http:// journals.openedition.org/hispanismes/13700 ; DOl: https://doi.org/10.4000/hispanismes. 13700

Este documento fue generado automáticamente el 27 enero 2022

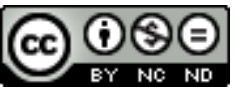

Les contenus de cette revue sont mis à disposition selon les termes de la Licence Creative Commons Attribution - Pas d'Utilisation Commerciale - Pas de Modification 4.0 International. 


\title{
Hilos conductores en la educación en México entre el Porfiriato y la posrevolución
}

\author{
El ejemplo del «Método Best»
}

Fils conducteurs dans l'éducation mexicaine entre le Porfiriato et la postrévolution: l'exemple de la "Méthode Best »

Threads in Mexican education between the Porfiriato and the post-revolutionary era: the example of the "Best Method"

\section{Élodie Vaudry}

El Método de dibujo, tradición y evolución del arte mexicano (fig. 1), como su título lo indica, tiene funciones múltiples: de enseñanza de dibujo, de creación de la nación y de proyección hacia el porvenir de la República Mexicana. Instrumento de propaganda bajo el gobierno de Álvaro Obregón (1921-1924), este libro se publicó en 1923 por la Secretaría de Educación Pública y se inauguró en la Escuela Nacional Preparatoria el 6 de noviembre del mismo año. ${ }^{1}$ Durante este periodo, José Vasconcelos, ministro de Educación Pública, le otorgó a Adolfo Best Maugard el título de Director de Dibujo y Trabajos Manuales. Su Método de dibujo, tradición y evolución del arte mexicano tuvo un tiraje de 15000 ejemplares y se utilizó solamente entre 1923 y 1924 en las escuelas primarias, normales e industriales. Este manual escolar se integró al proyecto cultural de Vasconcelos de difusión de nuevos símbolos mexicanos. ${ }^{2}$ Como fue mencionado, esta dinámica buscará la «regeneración de la especie, y salvará a los niños, educar a los jóvenes, redimir a los indios, ilustrar a todos y difundir una cultura generosa y enaltecedora ya no de una casta sino de todos los hombres». ${ }^{3}$ 
Figura 1: Adolfo BEST MAUGARD, Manuales y tratados. Método de dibujo. Tradición, resurgimiento y evolución del arte mexicano, México: Secretaría de Educación, 1923, página de portada y página de título

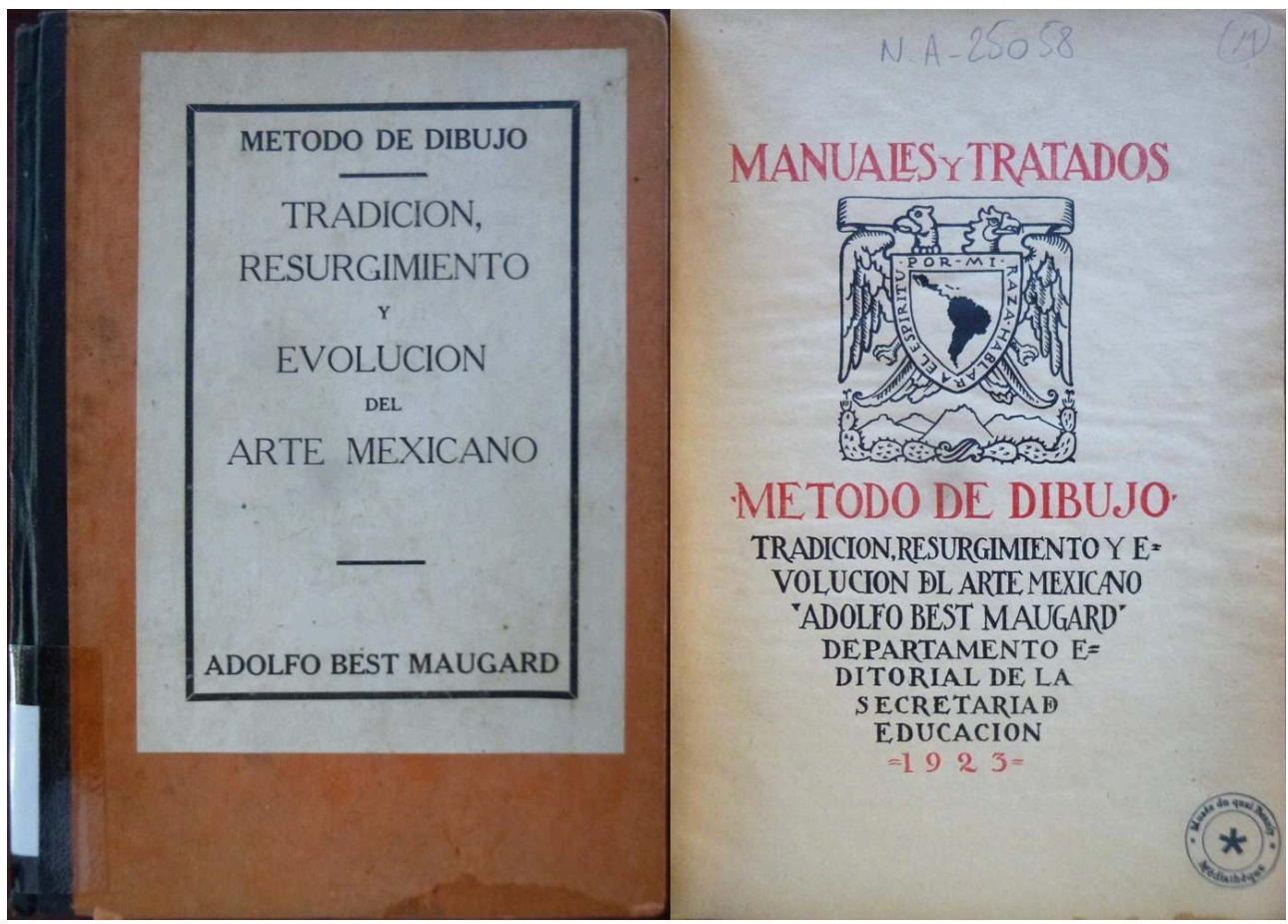

C)Fotografía personal, 2017

2 Aunque este proyecto lo sostenía el mismo Vasconcelos, la publicación de esta obra de alguna manera se presenta como puente entre algunas ideas de Justo Sierra, intelectual y político mexicano bajo el gobierno militar de Porfirio Díaz (1876-1910). Además, Best Maugard empezó su proyecto en 1911 pero lo publicó durante la época posrevolucionaria. De este modo, como lo anota Guillermo Hurtado, las ideas sobre la educación representan un hilo conductor entre los partidarios del positivismo mexicano y los miembros del Ateneo de la Juventud, asociación de intelectuales y artistas, de la que José Vasconcelos fue uno de los fundadores. ${ }^{4}$

De manera más precisa, el propósito de este artículo es analizar el Método de Best Maugard a través de las teorías educativas de Justo Sierra (1848-1912) durante el Porfiriato - el gobierno de Porfirio Díaz - y las del filósofo y político mexicano José Vasconcelos (1882-1959) después de la Revolución Mexicana. Los dos se caracterizan por su trabajo en el campo de la educación en México: el primero fundó la Universidad Nacional de México en 1910 y fue Secretario de Educación Pública y de Bellas Artes entre 1905 y 1911, mientras el segundo fue Rector de la Universidad Nacional de México de 1920 a 1921 y Secretario de Instrucción Pública de 1921 a 1923.

Gracias a Las Obras Completas (1977) de Justo Sierra, en particular La educación nacional. Artículos, actuaciones y documentos, asimismo las publicaciones de José Vasconcelos como El monismo estético (1918), La raza cósmica (1925), Robinsón a Odiseo (1935), Lecturas clásicas para niños (1924), proponemos una lectura inédita de la obra de Adolfo Best Maugard analizada a partir del contexto educativo en México al principio del siglo XX. La selección de estas dos referencias para explicar este manual escolar se justifica en varios puntos. Primero, porque compartieron algunas de las expectativas sobre la educación mexicana: para ambos la educación debe ser laica, gratuita, debe alimentar y 
educar a todos, sin distinciones de origen cultural y social. ${ }^{5}$ Segundo, mientras Vasconcelos era rector de la Universidad Nacional de México, operó una fusión del modelo original de la institución promovido por Sierra con un nuevo proyecto revolucionario. ${ }^{6}$ Aunque estos dos intelectuales pertenecieron a distintas escuelas de pensamiento - Sierra estuvo a favor de la evolución humana por el progreso del noeducado hacia el ciudadano ejemplar y Vasconcelos a favor de una revolución creadora hechas para educar y generar una quinta raza «cósmica»-, tuvieron la misma voluntad de educar a la nación. La filiación es tan obvia que cuando Vasconcelos empieza su función en la SEP, afirma que debe «recoger los hilos de lo que había dejado sin concluir Sierra». ${ }^{7}$

5 Demostrar la filiación intelectual del Método de dibujo, tradición y evolución del arte mexicano de Best Maugard permite abrir nuevas pistas de reflexión sobre un tema que interesa cada vez más los investigadores. En 1985, Karen Cordero es de una de las primeras intelectuales que se interesó al autor del manual y a su obra en su artículo «Para Devolver su Inocencia a la Nación. Apuntes y Desarrollo del Método Best Maugard $»^{8}$. La especialista del arte mexicano investigó varias veces el artista, especialmente sus fuentes visuales, sus impactos en los procesos indigenistas del gobierno de Álvaro Obregón y sus relaciones con la escena artística de México al principio del siglo XX. En 2002, Mireida Velásquez terminó su tesis de licenciatura Nacionalismo y vanguardia en la obra de Adolfo Best Maugard (1910-1923)' los vínculos estrechos entre el nacionalismo y la publicación y también entre la teosofía y las aspiraciones de Best Maugard. Con la misma idea de contextualizar el manual de dibujo, este artículo se propone centrarse sobre la coyuntura educativa en México y urdir las filiaciones intelectuales entre dos épocas - Porfiriato y pos-revolución interrumpidas por la Revolución mexicana de 1910.

6 En primer lugar, el análisis tratará de demostrar cómo los conceptos de la educación de Sierra y Vasconcelos se transcriben en el Método Best, particularmente en la elaboración de la noción de Patria, de religión laica y de afirmación anti-occidental. Luego, estudiaremos cómo estos intelectuales promueven la construcción nacional a través de la teoría del orden y de la homogeneización de las culturas mexicanas. Al final, reflexionaremos sobre las relaciones estrechas entre el campo de la educación, del arte y del desarrollo individual del ciudadano mexicano. En particular, nos centraremos en la concepción del niño propia del periodo y el deber social de la juventud mexicana de elevar su propia conciencia para alimentar el deseo mexicano de progreso.

\section{Educar para «forjar la Patria»}

7 El Método de dibujo contempla uno de los principales ejes del nacionalismo: utilizar la educación para «forjar la Patria» y proyectarla hacia un porvenir más glorioso, cuyas expectativas mexicanas son los modelos del progreso intelectual, político y económico europeos. Este libro participa en el afán de valorización del arte popular asociado al proyecto cultural nacionalista que promulga Álvaro Obregón cuando asume la función de Presidente de México en 1920. Según Karen Cordero, este gobierno

Inicia una campaña de reformas sociales, y una política cultural destinadas a reconciliar y a integrar los diversos grupos y clases de la sociedad mexicana. La educación, en este proyecto, desempeña un papel importante, y en el programa de Vasconcelos concentró el $20 \%$ de presupuesto nacional. ${ }^{10}$ 

pueblo alrededor de ideas, imágenes y deseos comunes. En el «Método Best» se propaga la voluntad de encontrar la esencia de la patria a través de los dibujos. Best Maugard, en su manual, valorizó los motivos patrióticos y insistió sobre la importancia de tener un repertorio visual común a toda la República mexicana. Así, el Método trata de poner de relieve el «alma nacional» mexicana. Best Maugard afirma que «el arte popular es ante todo la expresión sintética del alma de un pueblo» ${ }^{11} \mathrm{y}$ en este sentido, José Juan Tablada, autor del prefacio del manual de Best Maugard, afirma que la obra de arte «es un acto de religión».12

oda a la Patria y sus vínculos con el arte percibido como una «oración» de la nación ya existía en el Porfiriato cuando Justo Sierra dijo que «hacer puro arte es hacer Patria» ${ }^{13}$. Esta transposición del arte como religión de la Patria está también presente en los discursos de Vasconcelos, cuyo vocabulario es voluntariamente patrióticoreligioso. Según él, el artista es «el alma del tiempo» y la ornamentación expresa «lo que quiere ser nuestra alma propia»; el arte es el alma, no solamente del pasado que transpira en la creación contemporánea o la Patria presente, sino también en la nación futura. El alma representada por los motivos de Best o por las palabras de Vasconcelos es un alma atea, diacrónica y profundamente estética. Más allá del «alma mater», la educación tiene la misión de civilizar, «evangelizar» ${ }^{14}$, «propagar la fe» con un «ardor evangélico» y un «fervor apostólico». ${ }^{15}$

En el periodo posrevolucionario, la religión se desplaza de la iglesia hacia la República : ya la creencia no se dirige hacia un dios omnipotente, pero más bien hacia la Patria como figura del nuevo salvador que promete el acceso a la civilización. Con anticipación, el campo de la educación empujó esa dinámica en 1905, cuando el gobierno mexicano aprobó la ley de Justo Sierra sobre la educación primaria de carácter nacional, integral, laica y gratuita. ${ }^{16}$ Percibida como una responsabilidad social, la educación debe, según Sierra y los positivistas, servir la Patria, desarrollar el amor por la nación, contribuir al progreso del país y dar a la ciencia su posición central, porque solamente ella «protege la Patria». ${ }^{17}$ Más allá de esta postura radical, Justo Sierra «considera así la función del maestro de escuela, [que] pasa de ser una rutina para convertirse en un apostolado» y afirma que «la religión es el cáncer de la enseñanza porque falsea a la ciencia». ${ }^{18}$ Transmitir la «religión de la Patria» a los educandos y utilizar el sistema educativo para construir la Historia de la Patria y consolidar una personalidad nacional era el deseo tanto de Sierra como de Vasconcelos, lo que se encarnó en el libro de Best, cuando éste escribió que

todo pasa; los países, las razas y las civilizaciones desaparecen; pero muchos de sus artes aun subsisten. Desde este punto de vista es innegable que fomentar la evolución del arte nacional - y con esto queremos decir arte popular - es hacer nacionalidad, es hacer patria. ${ }^{19}$

11 Para elaborar un repertorio visual nacional, Best Maugard seleccionó y transformó varios símbolos en su manual, como el nopal, el águila y la tehuana. Dentro de ese proceso dialéctico formal, el autor transmutó las formas prehispánicas y indígenas en un motivo esquematizado y contemporáneo y las integró en el presente dándole un valor histórico. En otras palabras, el significado simbólico de estas formas era aniquilado en favor de un motivo nacional que, a través de la metonimia, ya no llevaba una cultura particular, sino todas las culturas mexicanas, pasadas y presentes. Durante esta transmutación, las formas antiguas y contemporáneas perdieron su significado

HispanismeS, 17 | 2021 
preciso - símbolo de sacrificio, agua, montañas - y se convirtieron en los partidarios de una identidad nacional de la misma manera que una bandera - observar el águila sobre una chumbera en el centro de la bandera mexicana que se refiere directamente a la historia azteca.

El enfoque nacionalista mexicano implica, por una parte, un rechazo de lo extranjero, especialmente la Academia europea. Juan Tablada escribe en la introducción del Método que «los cuadros de caballete» son una "aberración»" ${ }^{20}$ lo que es una referencia explícita a los cánones estéticos europeos. El arte no debe ser una copia o una asimilación de los modelos occidentales sino una creación basada sobre la realidad plástica mexicana - los paisajes, los colores y lo social- pintar los hábitos y atributos mexicanos. ${ }^{21}$ Best Maugard en su Método ${ }^{22}$ y Vasconcelos en un discurso de $1922^{23}$ aconsejan estimular a los niños con lo que ven en el hogar, en la calle, en sus juegos, etc. Aunque esta correspondencia entre el arte, la escuela y la vida se vincula estrechamente con las teorías alemanas de la época, especialmente con la de la Bauhaus: arte y vida, una unidad, así como con las ideas sobre la educación activa de John Dewey en Estados Unidos, donde los discursos educativos toman un tono claramente humanísticos y antiimperialistas. ${ }^{24} \mathrm{Al}$ excluir lo ajeno, este proceso de construcción nacional incluye, obviamente, los elementos vernáculos y, gracias a esto, integra y homogeneiza a los indígenas con el resto de la sociedad.

Así, entender las ideas del nacionalismo mexicano de Justo Sierra, José Vasconcelos y Adolfo Best Maugard tal como el concepto de Patria como religión nacional, el rechazo de las normas artísticas europeas para enfocarse sobre las fuentes mexicanas que Best Maugard valorizó en su manual de dibujo, permite construir una filiación intelectual inédita. Generalmente percibida como una ruptura con el Porfiriato, la Revolución de 1910 no interrumpió las expectativas educativas mexicanas, particularmente su papel en la construcción de la nación. Al contrario, la identidad nacional se presenta como un motivo pictórico en el caso del método escolar de Best Maugard o abstracto en el caso de J. Sierra y J. Vasconcelos. Estos tres autores aspiran a las mismas etapas civilizadoras : utilizar los medios educativos para forjar el sentimiento de la unión patriótica y enseñar la idea de lo «mexicano» por los dibujos son los fundamentos para homogeneizar, primera etapa antes de llegar a un estatuto de país «civilizado».

\section{Homogeneizar para civilizar}

Una de las condiciones del nacionalismo es la homogeneización de la nación: un pueblo unificado, que comparte el mismo idioma, los mismos códigos sociales, políticos y visuales. No obstante, el problema principal de México, identificado por varios intelectuales como Justo Sierra, Alfonso Caso y José Vasconcelos, es la heterogeneidad del país, su falta de unidad racial, cultural, social, etc. En su libro La educación nacional, Justo Sierra, Secretario de Educación Pública durante el Porfiriato, de 1905 a 1911, considera que hay que crear un sistema nacional de enseñanza para uniformar la instrucción mexicana. ${ }^{25}$ Por su lado, Vasconcelos prefiere el medio de la estética para homogeneizar la República a través de las normas creativas llamadas «idiomamotivos». ${ }^{26}$ Más allá de la nivelación cultural, el «Maestro de América» propone una «estética fundamental» basada en la Crítica del juicio de Immanuel Kant. Parafrasea el filosofo alemán afirmando que reuniría en «un principio de unidad súper-sensible las diversas series heterogéneas: el fenómeno, la noción moral y el sentimiento estético» ${ }^{27}$ 
Best Maugard coincide con él cuando afirma claramente que el «arte es la representación humana de la armonía universal». ${ }^{28}$ Afirma también que el movimiento (social, artístico, etc.) «debe ser colectivo» y que por eso hay que «reducir la expresión a la tradición para hacerlo homogéneo». ${ }^{29}$ Para comprobar esas ideas, Best Maugard publica en su método de enseñanza varios dibujos de sus alumnos. La publicación reúne dieciséis láminas, quince de las cuales son en color: la primera es un autorretrato completo en blanco y negro de Best Maugard de 1923, y las otras quince láminas son reproducciones de dibujos de estudiantes realizados según el método propuesto, probablemente durante las primeras pruebas del método en la Escuela Industrial Corregidora de Querétaro en $1918 .^{30}$ La inclusión de estos logros infantiles refleja el doble deseo de demostrar el éxito del método y comprobar la armonización artística como resultado de una generación de niños homogéneos creciendo con las mismas referencias visuales. La selección de dibujos se abre también a la imaginación de un niño mexicano de la época, uno de los cuales se llama «recuerdo» (fig.2), así como a los hábitos y costumbres, la fauna y la flora del país. Además, el estudiante neófito puede identificarse fácilmente plásticamente y culturalmente gracias al trabajo de sus predecesores. Una vez más, Best Maugard se basó en el registro de experiencias visuales y vínculos de identidad para fomentar una base educativa y cultural homogénea. Por último, la edición estratégica de estos dibujos otorgó un estatus especial a las creaciones de los niños: la mayoría de ellos están firmados por los alumnos y si el libro no incluye la lista de obras presentadas con referencias (nombres, medidas, fechas, etc.), sigue presentándolas en color y en papel brillante que tiene el mérito de resaltar la amplia gama cromática elegida por los alumnos.

Figura 2: Adolfo BEST MAUGARD, Manuales y tratados. Método de dibujo. Tradición, resurgimiento y evolución del arte mexicano, México: Secretaría de Educación, 1923, lámina color

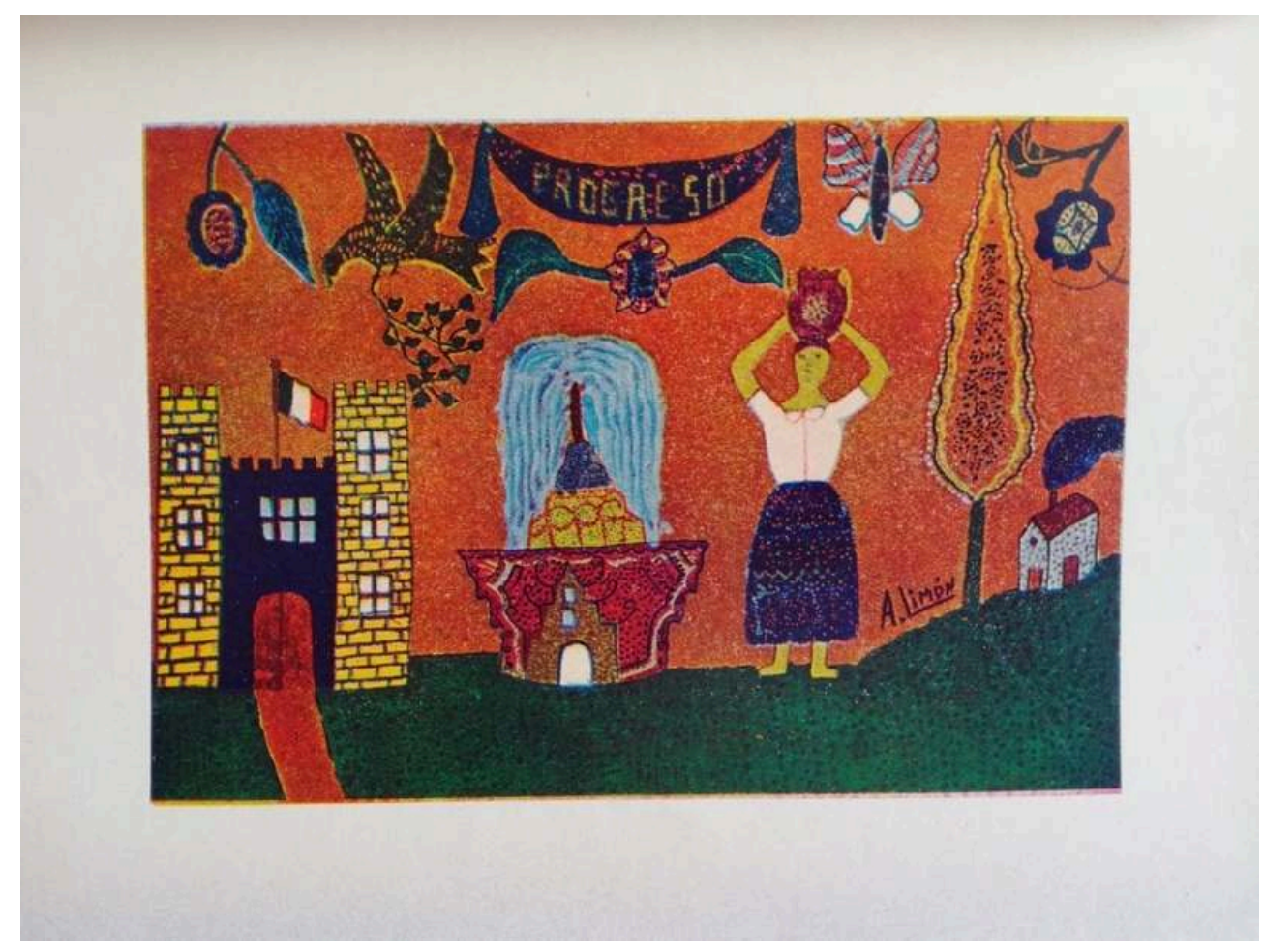

(C)Fotografía personal, 2017 
Paulatinamente, el indígena -o más bien la imagen que las elites tuvieron de él en esa época- se integra también a la sociedad mexicana por medio del arte. Si Justo Sierra se dedicó a la causa indígena cuando emprendió la misión de «hacerlos progresar» ${ }^{31}$, José Vasconcelos atacó de frente el problema gracias a su plan de incorporación del indígena. ${ }^{32}$ Esta preocupación de la política cultural proviene de la teoría del relativismo de Franz Boas, que Manuel Gamio recuperó en Forjando Patria, donde escribe que para unificar a la población, eran necesarias «una fusión de razas, la convergencia y la fusión de manifestaciones culturales, la unificación lingüística, [...] estas condiciones deben caracterizar a la población mexicana para que ésta constituya y encarne una Patria poderosa y una nacionalidad coherente y definida». ${ }^{33}$

Con este objetivo, la educación, la enseñanza y la difusión del castellano integra a los indígenas y homogeneiza a la población mexicana. ${ }^{34}$ Esta «hispanización» de la alfabetización se encuentra en el Método escrito en español y hecho para las nuevas escuelas mixtas. El manual, por sus referencias culturales y visuales mexicanas, indica una evidente complicidad entre el autor y sus lectores.

La instrumentalización de una memoria visual mexicana común pasa también por el descubrimiento, como lo escribió Best Maugard, de «las más remotas manifestaciones de nuestro arte aborigen, que constituyen los motivos originales». ${ }^{35} \mathrm{El}$ artista percibe en el indígena la «base de un sentimiento fuerte». ${ }^{36}$

18 La primera etapa en este proceso de homogeneización es la integración de las fuentes antiguas mexicanas. El autor del Método quiere operar una fusión entre las artes prehistóricas, prehispánicas, coloniales y populares para crear un verdadero arte nacional. Así, yuxtapuso un friso geométrico (fig.3) inspirado de los motivos del sitio arqueológico de Mitla (fig.4) en el estado de Oaxaca con grecas enrolladas similares a las pinturas murales de Teotihuacán en el estado de México. Como lo demostró Karen Cordero en su artículo «The Best Maugard drawing method: a common ground for modern mexicanist aesthetics $»^{37}$, Best Maugard mezcló motivos de cerámicas y lacas de varios estados mexicanos, particularmente de Michoacan, Jalisco y Guerrero. Así, el autor escogió su vocabulario visual en el repertorio prehispánico e indígena, reproduciendo motivos de canastas tradicionales, cerámicas toltecas y también de la fauna y la flora mexicanas. Las utilizaciones de estas fuentes antiguas están calificadas por Tablada de «necromancia» o de «autoridad de los muertos», única posibilidad de regeneración cultural y social de México. ${ }^{38}$ La cristalización del «carácter mexicano» y su materialización a través del arte manifiesta la idea común en la época de que la liberación espiritual lleva a la autonomía económica y forzosamente a la emancipación de Europa. ${ }^{39}$ Según las palabras de Vasconcelos, estos procesos pasan por una "admiración de lo que ya existe» ${ }^{40}$ en México: una valorización, a través de las imágenes, de los héroes nacionales para generar un «tejido cultural que ha de servir de carne y de sostén a la nueva aplicación biológica». ${ }^{41}$ 
Figura 3: Adolfo BEST MAUGARD, Manuales y tratados. Método de dibujo. Tradición, resurgimiento y evolución del arte mexicano, México: Secretaría de Educación, 1923, pp. 52-53


23. Desarrollo de grecas con la combinación de los elementos cuarto y quinto.



24. Desarrollo de grecas con la combinación de los elementos cuarto y sexto.

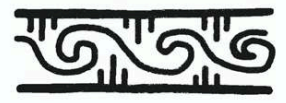

25. Desarrollo de grecas con la combinacion de los elementos cuarto y séptimo.

22. Desarrollo de grecas con la combinación de los elementos tercero y séptimo.

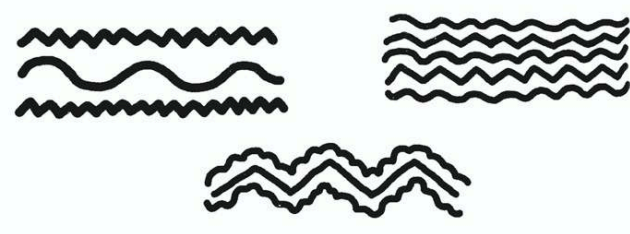

26. Desarrollo de grecas con la combinación de los elementos quinto y sexto.

(C)Fotografía personal, 2017

Figura 4: Detalles de una fachada del Palacio del Grupo de Columnas, 750-1500 D. C., civilización mixteca, Mitla, Estado de Oaxaca, México.

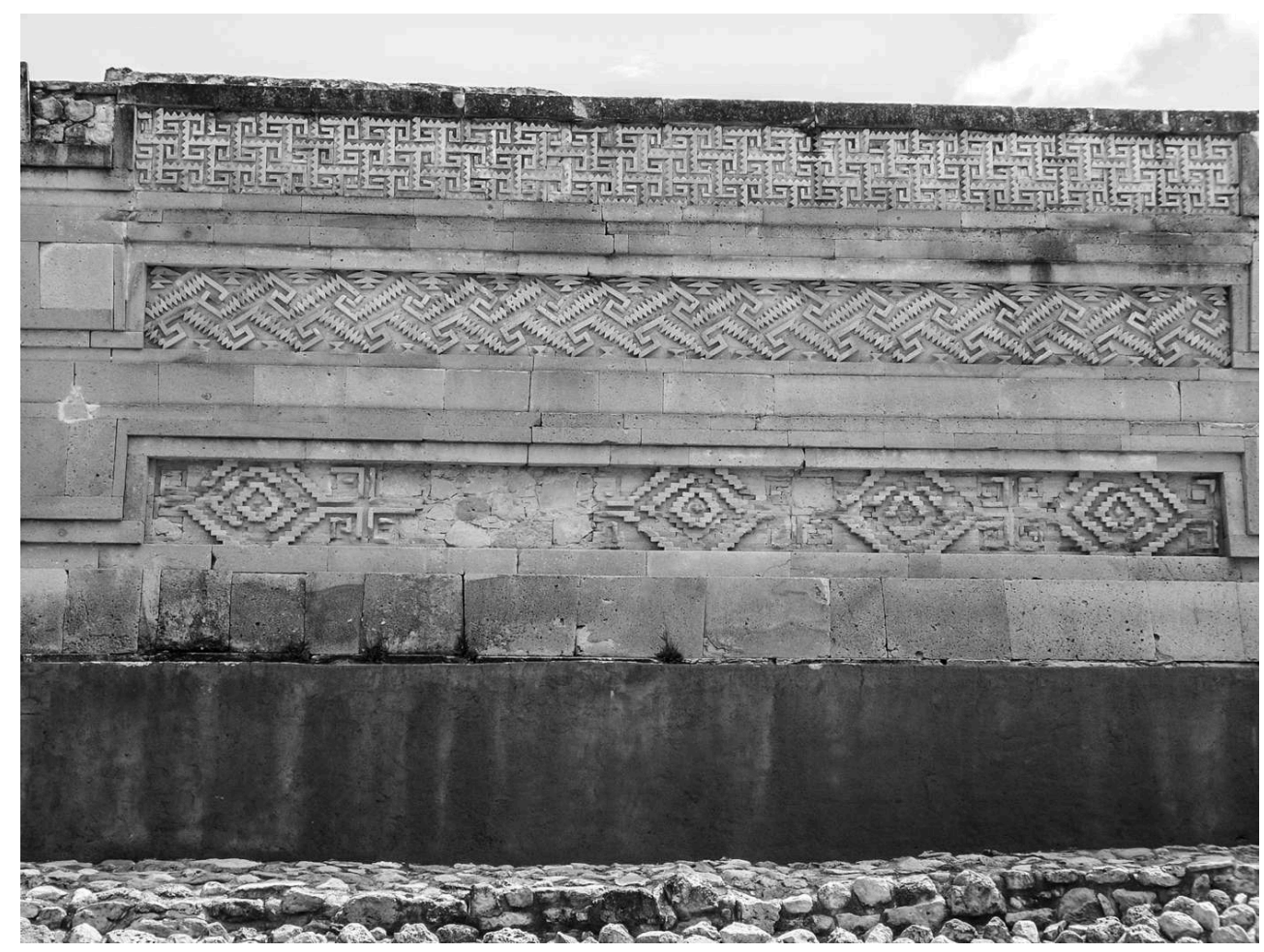

(C)Fotografía personal, 2011 
Figura 5: Adolfo BEST MAUGARD, Manuales y tratados. Método de dibujo. Tradición, resurgimiento y evolución del arte mexicano, México: Secretaría de Educación, 1923, p. 122-123.



(C)Fotografía personal, 2019

19 Cuando a través de su sistema Best Maugard trata de revelar «el auténtico arte mexicano ${ }^{42}$, hace hincapié también en las leyes estéticas universales, demostrando una técnica plástica que se puede aplicar a la enseñanza del dibujo. ${ }^{43} \mathrm{En}$ otras palabras, su ideal era establecer reglas artísticas fijas que puedan aplicarse a todas las culturas del mundo, no solamente latinoamericanas. Este universalismo se encuentra en la filosofía de Vasconcelos que concibe las escuelas de arte como un puente entre un nacionalismo vernáculo hacia una concepción universalista de la estética, cuya misión transcendental es la de "fundir lo humano en un tipo universal y sintético». ${ }^{44}$

Esta concepción universalista que concibe al mundo como un sistema dirigido y conceptualizado por la ciencia viene claramente del positivismo enunciado por Augusto Comte en la primera mitad del siglo xIx y difundido en México por Gabino Barreda a partir de 1867. De esta filosofía positivista -pero en la concepción de Herbert Spencer y John Stuart Mill- resulta la idea de un paralelo entre la evolución humana y la del nivel de una civilización: la educación, el progreso social y el desarrollo económico aparecieron como un vector hacia el progreso. ${ }^{45}$ En esta misma línea, Justo Sierra promovió el fortalecimiento de la libertad, el orden y el progreso a través de la educación para restablecer un poder fuerte en México, después de la anarquía que lo inundó posteriormente a la Independencia. ${ }^{46}$

21 Según el lema positivista «Libertad, Orden y Progreso», lo que Justo Sierra acogió por un tiempo, la educación es la primera etapa en el proceso evolucionista: solamente ella conduce a la libertad, que luego dirige al orden y al progreso. Por consiguiente, el campo educativo tiene que incluir una enseñanza que refleja el ordenamiento del futuro ciudadano. ${ }^{47}$ 

debates que se dieron en Europa, Estados Unidos y México al final del siglo xIx, particularmente en torno al debate entre una escuela que instruya - aprender a leer, escribir, contar, etc., y una que eduque - formar la moral, la vida práctica, etc. ${ }^{54} \mathrm{El}$ campo educativo se vuelve un área de formación para la vida. A través de estos presupuestos, se desarrolló la idea de la conciencia «pura» del niño: es esta pureza la que la educación debe elevar, modelar sin quitar su libertad creativa. cuyo sentido innato se acerca a la esencia de la cultura "pura», sin contaminación de la civilización que lo aleja del «poder creador». Best estableció una amalgama, común en esta época, entre el proceso evolutivo del niño y el de la civilización. En este sentido, el niño representa el amanecer de la nación y hay que animar esta inocencia que se percibió como equivalente a la del hombre primitivo. ${ }^{55} \mathrm{El}$ método aplica entonces unos de los preceptos de la modernidad, especialmente la amalgama entre el «primitivismo», 
la niñez, el «salvaje» contemporáneo y las culturas antiguas. Alicia Azuela de la Cueva afirma que «el sistema de enseñanza espontaneísta, al igual que el Método Best, estaba ligado con otros sistemas educativos interesados en el primitivismo y fue común que personajes importantes dentro del arte, la etnología y la psiquiatría siguieran su desarrollo». ${ }^{56}$ La autora toma el ejemplo del médico francés Pierre Janet que vino a México en 1925 y difundió su teoría sobre las equivalencias entre la creación artística de los niños y los esquizofrénicos con mentalidad primitiva. ${ }^{57}$

José Vasconcelos desarrolla también este paralelo en sus libros, sustentando que el proceso dialéctico de la expresión objetiva procede de un estado de sorpresa, un goce juvenil e imágenes virginales. ${ }^{58} \mathrm{El}$ tema de la «virginidad» cultural es recurrente en su obra y simboliza la obsesión del periodo por la pureza y la idea que tuvieron de lo «auténtico». Según él, solamente «la mañana del pasado contiene hitos sanos donde podemos enraizar el crecimiento» de la nación. ${ }^{59} \mathrm{En}$ su libro De Robinsón a Odiseo, Vasconcelos demuestra su profundo conocimiento de las teorías educativas extranjeras, como la de Rousseau, por ejemplo, que hizo un paralelo entre el niño y el «buen salvaje». Aunque el autor rechaza el método del filósofo francés por considerarlo demasiado sentimentalista, parece influenciado por este paralelo que Jung también utilizó en su trabajo, con el cual Vasconcelos estuvo familiarizado.$^{60}$ En este mismo libro publicado en 1935 (aunque las ideas germinales se encuentran desde la década de 1910), afirma que el objeto esencial de la educación es la de «rescatar en el grano el germen» y que esta esencia ayudará «a construirnos el destino». ${ }^{61}$ Esta pedagogía propiamente social se inspira directamente del pedagogo norteamericano John Dewey que considera la educación como «una necesidad biológica, una función social, un medio de dirección y un factor de crecimiento». ${ }^{62}$ Aunque Vasconcelos en De Robinsón a Odiseo rechaza la teoría de Dewey, afirmando que no es aplicable en México, es obvio que estos conceptos coinciden con su filosofía. ${ }^{63}$

Así, el aprendizaje de los motivos tiene una primera función educativa: despertar la intuición e instrumentalizarla para, según las palabras que Vasconcelos usa en $\mathrm{El}$ monismo estético, «transformar su sensibilidad instintiva en conciencia intuitiva». En La educación nacional Justo Sierra insiste sobre la libertad necesaria de la instrucción para estimular la originalidad y la espontaneidad del espíritu creador. Compartiendo esta idea, durante su discurso en Washington en 1922 Vasconcelos dijo que "educar es preparar al individuo para determinado propósito social». ${ }^{64}$ Estas ideas se encuentran en las palabras de Juan Tablada en su introducción al Método de dibujo, tradición y evolución del arte mexicano cuando elogia a José Vasconcelos diciendo que «su acción, especialmente en las artes plásticas, es decisiva y salvadora» y que este mismo arte tiene una función social directa. ${ }^{65}$ Adolfo Best Maugard pone en práctica estos conceptos educativos desde las primeras páginas de su libro. Presenta su fórmula plástica compuesta por siete motivos - la línea recta, el círculo, el semicírculo, el dibujo $\mathrm{S}$, la línea ondulada, el zig-zag y el almirante. Estas formas deben servir de base para el desarrollo de un lenguaje plástico que sea primero mexicano y después universal. Al intentar sintetizar el repertorio visual mexicano, el autor educa al niño ofreciéndole motivos que considera intuitivos y emocionales, pero también una dinámica educativa de aprendizaje de la tradición y la práctica repetitiva. Según él, la copia de estos siete motivos y su asimilación para que sean obvios y mecánicos debería ayudar a los alumnos a dinamizarse, a ganar confianza en su potencial creativo y social. ${ }^{66}$ 
El vocabulario que utiliza Vasconcelos es sintomático: hay que «despertar la intuición $»^{67}$ y cultivar «su sensibilidad instintiva» ${ }^{68}$; en otras palabras, el papel del maestro y el del gobierno es animar algo en los niños que ya existe. Este campo semántico pone de realce la creencia del Secretario de la SEP y la de sus contemporáneos: los educandos tienen en sí mismos la esencia de la nación.

En el manual, el autor trata de despertar lo innato del alumno que, según él, está latente en cada uno de los niños. Así, Best Maugard utiliza los motivos antiguos prehistóricos, prehispánicos- y vernáculos -indígenas- (fig. 3) y un aprendizaje progresivo y lento de estas formas para reactivar el sentido visual y plástico de la juventud mexicana. Su sistema preconiza un aprendizaje de lo más sencillo a lo más complejo, con ejercicios al final que permiten ir y volver entre varios niveles para generar una mejor incorporación de los motivos (fig. 3). En su método lo sencillo se traduce en la práctica de los primeros dibujos con líneas simples, después viene la fase del plano en dos dimensiones para dominar la concepción del volumen, y finalmente invita a los alumnos a mezclar los distintos planos. Más allá de estas tres etapas, para realizar un buen conjunto decorativo, los educandos deben dibujar motivos armónicos, bien repartidos, equilibrados, simétricos, simples e ingenuos. ${ }^{69}$

Este tipo de progresión del dibujo lineal se encuentra en las teorías de Johann Heinrich Pestalozzi que recomienda empezar por las formas simples (dibujo lineal), continuar con formas geométricas y terminar con figuras más complicadas. ${ }^{70} \mathrm{El}$ pedagogo suizo aconseja también desarrollar la enseñanza a partir de la percepción sensible de la naturaleza para despertar sensaciones visuales originales y «puras». ${ }^{71}$

La valorización y la búsqueda de la intuición en la educación primaria son dos puntos desarrollados en las teorías del educador mexicano Enrique Rébsamen y se usan en las escuelas de Pintura al Aire Libre. El fundador y director de esas escuelas Alfredo Ramos Martínez, construyó una metodología educativa intuicionista que valoriza la creación infantil, «como reflejo de la expresión más pura y espontánea». ${ }^{72}$ Estas líneas plásticas y educativas coinciden en el manual de Best Maugard : los alumnos de la primaria y la secundaria utilizan los mismos métodos de aprendizaje que los jóvenes pintores mexicanos. El autor aconseja a los niños dibujar su casa, sus objetos, la fauna y la flora mexicanas, etc. Desarrollando su instinto creador y descubriendo su país, el niño se eleva y se vuelve un futuro ciudadano mexicano. Así lo anota Best Maugard en su introducción, «lo principal [por el alumno] es descubrir la intención», el «carácter propio» de su alma y de su país. ${ }^{73}$ Justo Sierra va más allá de esta dinámica cuando afirma que la educación prepara «personas a ser Hombres» y «consiste en la formación del corazón y del carácter». ${ }^{74}$ Vasconcelos se acercó a esta idea, diciendo que «cada hombre es un motivo potencial que transforma el idioma-motivo» y que la «intuición estética», más bien el « ritmo ético » exalta la personalidad del individuo. ${ }^{75}$ Así, en estas afirmaciones podemos poner de relieve que la educación permite la valorización y la elevación del individuo como ser único con un potencial creador. Esta concepción encuentra paralelos con la de Jean-Jacques Rousseau quien consideraba que la educación era un medio para formar al hombre para sí mismo y para la sociedad. ${ }^{76}$ Como lo nota María Esther Pérez Salas, la amalgama entre la enseñanza del dibujo y la marcha del progreso también pudo haber venido desde Francia que a principios del siglo xIX instrumentalizó el dibujo con el objetivo de preparar a los obreros y artesanos para las necesidades de la revolución industrial. ${ }^{77} \mathrm{El}$ dibujo permitió reducir la dependencia tecnológica del país, regenerar la moral popular y ordenar la sociedad. ${ }^{78}$ 
Este punto de vista se cruza con el de Anatoly Vasilyevich Lunarcharsky, comisario de la educación rusa e inspiración de Vasconcelos ${ }^{79}$, quien concibió el arte del pasado como una base de conciencia histórica y una motivación para el proletario ruso, hacia la creación de un futuro nacionalista. ${ }^{80}$

Para llegar a esta evolución mental, como lo notan Best Maugard y Vasconcelos, el dibujo procede de un conjunto de esfuerzos. El Método de dibujo, tradición y evolución del arte mexicano permite, según las teorías de estos autores, realizar una transmutación entre el aprendizaje lineal y moral, entre una práctica manual y una práctica conceptual. Las repeticiones de los motivos se vuelven una praxis luego o, en el sentido de Aloïs Riegl, un Kunstwollen, en donde un motivo se transforma en arte con una voluntad humana.

Esta concepción del aprendizaje como movimiento ascendente del alma se vincula estrechamente con la teoría de la pedagogía «estructurativa» de Vasconcelos. Según él, la enseñanza se concibe como una experiencia que se desarrolla en la coacción entre el educador y el estudiante y que, como finalidad última de la educación, genera, el parto del alma. En este proceso, la estética -como intuición mística- aparece como la Séptima Sinfonía del sistema sintético del autor de la Raza cósmica. Este dinamismo estético se traduce por el ritmo plástico que es «una orientación del movimiento de nuestra alma hacia el estado de divinidad en que se realiza lo absoluto». ${ }^{81}$ En el «Método Best» este campo léxico se encuentra cuando el autor escribe que los «ritmo y armonía abstracta tienen que tomar forma real y plástica» ${ }^{82}$, y que «la greca es pues, algo semejante a la música, es meramente una expresión armónica que no representa más que eso: armonía y ritmo». ${ }^{83}$ Esta rítmica estética se observa en distintos niveles en su sistema: primero, el ritmo cadencioso del aprendizaje de los motivos; segundo, el ritmo de las formas que se organizan entre ellas, entre distintos planos para crear figuras; tercero, el ritmo de una coral unísona que homogeneiza la tradición visual de todo un país. Es interesante notar que en su texto de introducción al manual de Best Maugard, José Juan Tablada utiliza el mismo vocabulario «musical» que Vasconcelos, asintiendo que es necesario dar «un ritmo jubiloso y sinfónico a nuestro trabajo». ${ }^{84}$

Adolfo Best Maugard, Justo Sierra y José Vasconcelos coinciden una vez más: la educación artística debe ser capaz de despertar en los niños el ADN de la nación. La práctica del dibujo invitará a la memoria profunda de la juventud mexicana, según estos tres autores, a revivir los motivos prehispánicos, a valorar e integrar las creaciones indígenas y a preparar la futura identidad nacional. Además, la educación, en los respectivos escritos de los autores analizados, permite llegar a los instintos personales e interiores de los niños, cuya única función es establecer un molde común para esculpir un modelo y ciudadano civilizado.

\section{Conclusiones}

36 El «Método Best» representa la voluntad de regeneración nacional de los gobiernos mexicanos a principios del siglo XX. Este trabajo permite apreciar los resultados directos de las teorías de la educación de Justo Sierra durante el Porfiriato y de José Vasconcelos durante el gobierno de Álvaro Obregón. Percibido como uno de los procesos más relevantes de la construcción nacional, el campo educativo sirvió de base reflexiva por estos dos gobiernos para construir el porvenir de la nación, de los niños y de cada ciudadano mexicano. Además, la comparación de las ideas de estos dos 
intelectuales a través del manual de Best Maugard ha permitido mostrar los hilos rectores que se tejieron entre las épocas pre- y pos-revolucionaria. Así, a través de la educación Justo Sierra y José Vasconcelos compartieron algunas de las ideas fundamentales para la elevación social y espiritual de las próximas generaciones, entre ellas la escuela laica, gratuita y centro de formación de la vida cotidiana y ciudadana. Además, el estudio del Método de dibujo, tradición y evolución del arte mexicano permite entender la concepción del niño como vector del pasado y del futuro, como medio para revitalizar la memoria nacional y la educación de la juventud mexicana como herramienta para homogeneizar la población de México.

Este análisis hizo hincapié también en los distintos niveles de recepción y utilización del libro, así como en el poder artístico que tiene, como lo identifica Tablada, «en un tiempo mismo una función individual, una función nacional y una función humana». ${ }^{85}$ En este sentido, la educación y la cultura son inseparables; tanto su teorización como sus aplicaciones en esa época coinciden significativamente con otros factores interdependientes, a saber, con la política y la economía. ${ }^{86}$

Así, hay que leer este manual como libro iniciático que conduce al estudiante de un estado de naturalidad a un estado de hombre civilizado. La evolución que se propone en esta publicación lleva al hombre-innato y heterogéneo desde su saber intuitivo, incontrolado e inactivado hacia el hombre civilizado y homogéneo por la domesticación de sus sentimientos y de su razón. El libro se basa sobre motivos antiguos para preparar el futuro de México. El discurso teórico «imagen-idioma» debe llevar a los alumnos a la práctica nacionalista: la de actuar para y por su país, en ciudadano activo, productivo y patriótico. Las teorías de Justo Sierra y de José Vasconcelos denotan la voluntad de sistematizar un proceso humano. En otras palabras, el manual de Best Maugard propone una aplicación sistemática con esquemas fijos que pueden emplearse en las distintas capas de la sociedad, distintas culturas y países del mundo. En suma, el Método es un sistema determinado por leyes gráficas y pedagógicas que producen una ley estética única, como medio hacia a la conciencia cósmica según Vasconcelos.

\section{BIBLIOGRAFÍA}

AZUela DE LA CueVa Alicia, Arte y poder, México, Fondo de Cultura Económica, 2013.

BEST MAUGARD Adolfo, Método de dibujo. Tradición, resurgimiento y evolución del arte mexicano, México, Secretaria de Educación, 1923.

CAMPOS-BADILla Xinia, «Influencia de los postulados de Jean-Jacques Rousseau, Johan Heinrich Pestalozzi, Antonio Rosmini-Serbati, Johann Friedrich Herbart y Karl Marx sobre las Teorías de la Educación de Siglos XX y XXI», Acta Academia, n59, 2016, pp. 19-34.

CORDERo Karen, «Para devolver su inocencia a la Nación. Apuntes y desarrollo del método Best Maugard», [sin autor], Abraham Àngel y su tiempo, México, museo nacional de San Carlos, 1985, p. 9-19. 
CORDERO Karen, «The Best Maugard drawing method: a common ground for modern mexicanist aesthetics», en The Journal of Decorative and Propaganda Arts, vol. 26, México, 2010, pp. 44-79. DEWEY John, Démocratie et éducation : introduction à la philosophie de l'éducation, París, L'Âge d'Homme, 1944. [1 ${ }^{\text {ra }}$ edición en 1916]

FELL Claude, José Vasconcelos. Los años del águila, México, UNAM, 2009.

FOUCAUlT Michel (1971), «L’ordre du discours», [en línea] París, Collège de France, 1971. [consultado el 11 de mayo de 2020] <URL: http://1libertaire.free.fr/Foucault64.html>. GALVÁN LAFARGA Luz Elena, "Creación de la Secretaría de Educación Pública», Luz Elena GALVÁN LAFARGA y Miguel Ángel oSORIO CHONG, Derecho a la educación, Mexico, UNAM, 2016, pp. 109-138.

GAMIo Manuel, Forjando Patria, México, Porrúa, 1916.

GONZAlbo AizPuru Pilar, StAPles Anne, Historia de la educación en la Cuidad de México, México, Colmex, 2012.

GRIMBERG Salomon, «Un Caballero educado», en Adolfo Best Maugard, La espiral del arte, museo del Palacio de Bellas Artes, centro culturel Jardín Borda,, México, Instituto nacional de Bellas Arte, pp. 19-54.

HERBERT PÉREZ Guillermo, «Presentación», José Vasconcelos, De Robinson a Odiseo. Pedagogía estructurativa, Monterrey, Senado de la República, 2002, pp. 7-9. [1 $1^{\text {ra }}$ edición en 1935] HURTADO Guillermo, La revolución creadora. Antonio Caso y José Vasconcelos en la Revolución mexicana, Mexico, UNAM, 2016.

KAY VAUGHAN Mary, Estado, clases sociales y educación en México, México, Fondo de cultura económica, 1982.

LIRA GONZÁLEZ Andrés, «Los indígenas y el nacionalismo mexicano», El nacionalismo y el arte mexicano, IX Coloquio de Historia del Arte, México, UNAM, 1986, pp. 19-34.

OCAMPO LÓPEZ Javier, «Justo Sierra», El Maestro de América« Fundador de la Universidad Nacional de México», Revista Historia de la Educación Latinoamericana, n¹5, 2010, pp. 13-38.

PÉREZ SALAS Maria Esther, «Los manuales de dibujo decimónicos», Aurelio DE LOS REYES, La enseñanza del dibujo en México, México, UNAM, 2014, pp. 68-69.

REYES Aurelio de los, La enseñanza del dibujo en México, México, UNAM, 2014.

RODRÍGUEZ MORTELLANO Itzel, «El renacimiento posrevolucionario de Quetzalcóatl», La imagen política, XXV coloquio internacional de historia del arte, México, UNAM, 2006, pp. 335-354.

SENA Juan del (José D. Frías), «Best Maugard y su sistema de enseñanza artístic», en El Universal Ilustrado, 6 de julio de 1922, p. 35.

SEVERI Carlo, «L'univers des arts de la mémoire. Anthropologie d'un artefact mental», Annales HSS, $\mathrm{n}^{\circ} 2$, (marzo-abril 2009), pp. 463-493.

SIERRA Justo, La educación nacional. Artículos, actuaciones y documentos, México, UNAM, Obras completas del maestro Justo Sierra, Tomo VIII, 1948.

TABLADA José Juan, «La función social del arte», Adolfo Best Maugard, Método de dibujo. Tradición, resurgimiento y evolución del arte mexicano, México, Secretaria de Educación, 1923. pp. XI-XXVII. 
VASCONCELOS José, De Robinson a Odiseo. Pedagogía estructurativa, Monterrey, Senado de la República, 2002. [ $1^{\text {era }}$ edición en 1935$]$

VASCONCELOS José, El monismo estético. Ensayos, México, Trillas, 2009. [1 $1^{\text {era }}$ edición en 1918]

VASCONCELOS José, La raza cósmica, México, Porrúa, 2017. [1 $1^{\text {era }}$ edición en 1925]

VELÁzQUEZ TORRES Mireida, Nacionalismo y vanguardia en la obra de Adolfo Best Maugard (1910-1923),

México, UNAM, tesis de licenciatura, 2002.

\section{NOTAS}

1. Mireida VelázQUEZ toRRES, Nacionalismo y vanguardia en la obra de Adolfo Best Maugard (1910-1923), México, UNAM, tesis de licenciatura, 2002, p. 29.

2. Karen CORDERO, «Para devolver su inocencia a la Nación. Apuntes y desarrollo del método Best Maugard», Abraham Àngel y su tiempo, México, museo nacional de San Carlos, 1985, p. 19.

3. Claude FeLL, José Vasconcelos. Los años del águila, México, UNAM, 2009, p. 59.

4. Guillermo HURTADO, La revolución creadora. Antonio Caso y José Vasconcelos en la Revolución mexicana, Mexico, UNAM, 2016, p. 21.

5. Claude FELL, op.cit., p. 58.

6. Guillermo HURTADO, op.cit., p. 203.

7. Luz Elena GALVÁN LAFARGA, «Creación de la Secretaría de Educación Pública», Derecho a la educación, Mexico, UNAM, 2016, p. 100.

8. Karen CORDERO, «Para devolver su inocencia a la nación. Apuntes y desarrollo del método Best Maugard», 1985.

9. Mireida VeLÁZquez TORRES, op.cit.

10. Karen CORDERO, «Para devolver su inocencia a la nación. Apuntes y desarrollo del método Best Maugard», op.cit., p. 18.

11. Adolfo BEST MAUGARD, Método de dibujo. Tradición, resurgimiento y evolución del arte mexicano, México, Secretaria de Educación, 1923, p. 14.

12. José Juan tABLADA, «La función social del arte», Adolfo Best Maugard, Método de dibujo. Tradición, resurgimiento y evolución del arte mexicano, op.cit., p. XVII.

13. Andrés LIRA GONZÁLEZ, «Los indígenas y el nacionalismo mexicano», El nacionalismo y el arte mexicano, IX Coloquio de Historia del Arte, México, UNAM, 1986, p. 19.

14. José VASConcelos, La raza cósmica, México, Porrúa, 2017, p. X.

15. Guillermo HURTADO, op.cit., p. 215.

16. Javier ocAmPo LóPEZ, «Justo Sierra», El Maestro de América« Fundador de la Universidad Nacional de México», Revista Historia de la Educación Latinoamericana, n¹5, 2010, p. 16.

17. Ibid, p. 17.

18. Justo SIERRA, La educación nacional. Artículos, actuaciones y documentos, op.cit., p. 20 y 34.

19. Adolfo BEST MAUGARD, op.cit., p. 17.

20. José Juan TABLADA, op.cit., p. XI.

21. Alicia azuela de la cueva, Arte y poder, México, Fondo de Cultura Económica, 2013, p. 49.

22. Adolfo BEST MAUGARD, op.cit., p. 125.

23. Claude FELL, José Vasconcelos. Los años del águila, op.cit., p. 170.

24. Alicia AZUela DE LA CUEVA, op.cit., p. 49.

25. Javier OCAMPO LÓPEZ, op.cit., p. 24.

26. José VASCONCELOS, El monismo estético. Ensayos, op.cit., pp. $20 ; 25$.

27. Ibid., p. 15. 
28. Adolfo BEST MAUGARD, op.cit., p. 1.

29. Adolfo BEST MAUGARD, ibid., p. 2.

30. Juan del Sena (José D. Frías), «Best Maugard y su sistema de enseñanza artístic», en El Universal Ilustrado, 6 de julio de 1922, p. 35.

31. Justo SIERRA, La educación nacional. Artículos, actuaciones y documentos, op.cit., p. 109.

32. Guillermo HURTADO, op.cit., p. 174.

33. Manuel Gamio, Forjando Patria, México, Porrúa, 1916, p. 325.

34. Claude FELL, op.cit., p. 31.

35. Adolfo BEST MAUGARD, op.cit., p. 6.

36. Ibid., p. 7.

37. Karen CORDERO, «The Best Maugard drawing method: a common ground for modern mexicanist aesthetics», en The Journal of Decorative and Propaganda Arts, vol. 26, México, 2010, pp. 76.

38. José Juan TABLADA, op.cit., p. XII.

39. Guillermo HERBERT PÉREZ, «Presentación», José Vasconcelos, De Robinson a Odiseo. Pedagogía estructurativa, Monterrey, Senado de la República, 2002, p. 7 [ $1^{\text {ra }}$ edición en 1935]

40. José VASCONCELOS, El monismo estético. Ensayos, op.cit., p. 20 [1era edición en 1918]

41. John DEWEY, Démocratie et éducation : introduction à la philosophie de l'éducation, París, L’Âge d'Homme, 1944, p. 326 [1 $1^{\text {ra }}$ edición en 1916]

42. Mireida VELÁZqUEZ TORRES, Nacionalismo y vanguardia en la obra de Adolfo Best Maugard (1910-1923), op.cit., p. 13.

43. Karen CORDERO, «Para Devolver su Inocencia a la Nación. Apuntes y Desarrollo del Método Best Maugard», op.cit., p. 11.

44. José VASCONCELOS, La raza cósmica, op.cit., p. 15.

45. Itzel RODRíGUEZ MORTELLANO, «El renacimiento posrevolucionario de Quetzalcóatl», La imagen política, XXV coloquio internacional de historia del arte, México, UNAM, 2006, p. 340.

46. Javier OCAMPO LÓPEZ, op.cit., p. 20.

47. Guillermo HURTADO, op.cit., p. 8.

48. José vasconcElos, El monismo estético. Ensayos, México, Trillas, 2009, p. 13.

49. Alicia AZUELA DE LA CUEVA, op.cit., p. 18.

50. Adolfo BEST MAUGARD, op.cit., p. 128.

51. José VASCONCELOS, El monismo estético. Ensayos, op.cit., p. 55.

52. Carlo SEVERI, «L'univers des arts de la mémoire. Anthropologie d'un artefact mental», Annales HSS, n² 2, (marzo-abril 2009), p. 477.

53. Michel foucault, «L'ordre du discours», París, Collège de France, 1971, s.p. [en línea <URL: http://foucault.50webs.com/books/1971_OD.htm>.

54. Pilar gonZalbo AizPuRu, Anne StAPLes, Historia de la educación en la Cuidad de México, México, Colmex, 2012, p. 342.

55. Karen CORDERO, «Para Devolver su Inocencia a la Nación. Apuntes y Desarrollo del Método Best Maugard», op.cit., p. 10.

56. Alicia AZUELA DE LA CUEVA, op.cit., p. 221.

57. Ibid., p. 221.

58. José VASCONCELOS, El monismo estético. Ensayos, op.cit., p. 19.

59. Ibid., p. 45.

60. José VASCONCELOS, De Robinson a Odiseo. Pedagogía estructurativa, Monterrey, Senado de la República, 2002, p. 14.

61. Ibid., p. 261.

62. Claude FELL, op.cit., p. 156.

63. José VASCONCELOS, De Robinson a Odiseo. Pedagogía estructurativa, op.cit., pp. 23-31. 
64. Salomon GRIMBERG, «Un Caballero educado», en Adolfo Best Maugard, La espiral del arte, museo del Palacio de Bellas Artes, centro culturel Jardín Borda,, México, Instituto nacional de Bellas Arte, p. 44.

65. José Juan TABLADA, op.cit., p. XXV.

66. Adolfo BEST MAUGARD, op.cit., p. 45.

67. Justo SIERRA, La educación nacional. Artículos, actuaciones y documentos, op.cit., pp. 23; 35.

68. Claude FELL, op.cit., p. 103.

69. Adolfo BEST MAUGARD, op.cit., p. 95.

70. Aurelio DE LOS REYES, La enseñanza del dibujo en México, México, UNAM, 2014, p. 86.

71. Ibid., p. 87.

72. Mireida VELÁZqUEZ TORRES, Nacionalismo y vanguardia en la obra de Adolfo Best Maugard (1910-1923), op.cit., p. 12.

73. Adolfo BEST MAUGARD, op.cit., p. 38.

74. Justo SIERRA, La educación nacional. Artículos, actuaciones y documentos, op.cit., pp. 12; 51.

75. José VASCONCELOS, El monismo estético. Ensayos, op.cit., pp. 25; 36; 42.

76. Xinia CAMPOS-BADILLA, «Influencia de los postulados de Jean-Jacques Rousseau, Johan Heinrich Pestalozzi, Antonio Rosmini-Serbati, Johann Friedrich Herbart y Karl Marx sobre las Teorías de la Educación de Siglos XX y XXI», Acta Academia, n59, 2016, p. 23.

77. Maria Esther PÉREZ SALAS, «Los manuales de dibujo decimónicos», Aurelio de los Reyes, La enseñanza del dibujo en México, México, UNAM, 2014, pp. 68-69.

78. Ibid., p. 68.

79. Guillermo HURTADO, op.cit. pp. 222-224.

80. Mary KAY VAUGHAN, Estado, clases sociales y educación en México, México, Fondo de cultura económica, 1982, tomo II, p. 436.

81. Luz Elena GALVÁN LAFARGA, op.cit., p. 111.

82. Adolfo BEST MAUGARD, op.cit., p. 2.

83. Ibid., p. 45.

84. José Juan TABLADA, op.cit., p. X.

85. José Juan TABLADA, ibid., p. XX.

86. Claude FELL, op.cit., p. 95.

\section{RESÚMENES}

Le propos de cet article est d'analyser le manuel de dessin de l'artiste mexicain Adolfo Best Maugard (1891-1964) à travers les théories éducatives de l'intellectuel et homme politique mexicain Justo Sierra (1848-1912) pendant le Porfiriato et celles du philosophe et homme politique mexicain José Vasconcelos (1882-1959) écrites après la révolution mexicaine. Tous deux se caractérisent par leur travail dans le domaine de l'éducation au Mexique : le premier a fondé l'Université nationale du Mexique et a été Secrétaire de l'enseignement public et des beaux-arts entre 1905 et 1911, tandis que le second a été Recteur de l'Université nationale du Mexique de 1920 à 1921 et Secrétaire de l'instruction publique entre 1921 et 1923. Ainsi, la Méthode de Best Maugard doit être considérée comme un catalyseur de ces deux écoles de pensées ou, plutôt, 
comme un élément qui représente l'ère post-révolutionnaire non seulement en termes de rupture mais aussi de continuité entre le $\mathrm{XIX}^{\mathrm{e}}$ et le XIX ${ }^{\mathrm{e}}$ siècle.

The purpose of this article is to analyze the drawing manual of the Mexican artist Adolfo Best Maugard (1891-1964) through the educational theories of the Mexican intellectual and politician Justo Sierra (1848-1912) during the Porfiriato and those of the Mexican philosopher and politician José Vasconcelos (1882-1959) written after the Mexican revolution. Both are characterized by their work in the field of education in Mexico: the first founded the National University of Mexico and was Secretary of Public Education and Fine Arts between 1905 and 1911, while the second was Rector of the National University of Mexico from 1920 to 1921 and Secretary of Public Education between 1921 and 1923. Thus, the Best Maugard Method must be considered as a catalyst for these two schools of thought or, rather, as an element that represents the post-revolutionary era not only in terms of rupture but also in terms of continuity between the 19th and 19th centuries.

\section{ÍNDICE}

Keywords: Adolfo Best Maugard, Justo Sierra, José Vasconcelos, Mexico, education Mots-clés: Adolfo Best Maugard, Justo Sierra, José Vasconcelos, Mexique, éducation

\section{AUTOR}

\section{ÉLODIE VAUDRY}

Centre allemand d'histoire de l'art, DFK, Paris 